\title{
The impact of social media followers on corporate value: An investigation of Australian firms
}

\author{
Patrick Mauder ${ }^{1}$ \\ ${ }^{1}$ Bond Business School, Bond University, \\ 14 University Drive, \\ Robina, QLD 4226, Australia \\ E-mail:pmauder@bond.edu.au
}

\begin{abstract}
With social media user numbers reaching billions, firms seek to partake in the benefits of investing into social media activities. Existing literature, however, provides little insight as to whether investment in social media adds value for corporations. In particular, it remains difficult to quantify the financial benefits for firms from social media activities. Prior research found uncertainty for small and large firms on whether value is derived from the information present on social media and the access to the large number of users. Based on a sample of 74 listed Australian firms for an observation period of 30 days of June 2016, this study examines the relationship between the firm's social media activities on Facebook, LinkedIn and Twitter and corporate value. The results show that a firm's social media presence on LinkedIn has a significant effect on the share return of firms, while a social media presence on Facebook and Twitter did not provide statistically significant results. Interestingly, the study also found that there is a difference between B2B and B2C firms, confirming a significant impact between for B2C firms on LinkedIn and share returns. The findings are useful for corporate managers and social media activists trying to understand the financial impacts of social media on corporate value.
\end{abstract}

Keywords: social media, corporate value, Facebook, LinkedIn, Twitter, B2B, B2C

\section{Introduction}

Social media is increasingly important for organizations and growing user numbers are seen as an opportunity to reach a large number of current and potential customers. In particular, Facebook, LinkedIn and Twitter are regarded as leading global social media networks with user numbers exceeding 1.8 billion for Facebook ${ }^{1}$, close to 467 million for LinkedIn ${ }^{2}$ and 317 million for Twitter ${ }^{3}$. Firms may obtain valuable insights from users' posts to those sites, utilise this knowledge in their production and marketing decisions, and subsequently increase the financial performance of the firm, creating value for shareholders. Moreover, investors and other firm stakeholders may find it useful to track the general sentiment and extent of social media attention on a firm and its operations. These types of data may provide information about current and potential customers' needs and intentions to transact with that firm. Accordingly, investors and other stakeholders may consider this knowledge relevant when making future investment decisions. Consequently, social media network user numbers may be value-relevant and is considered an area of potential value for business, yet quantifying the benefits of investing in social media is difficult.

As social media networks appear to continuously expand in terms of user numbers, the importance for firms to understand these implications are likely to increase 4,5 . Determining a relationship between social media network activity and corporate value will be useful to managers' understanding of the benefits of investing into this form of social media. For academia, this study contributes to the understanding of the relationship between social media network follower numbers as a signal for brand value and cumulative abnormal return as a proxy for corporate value.

The aim of this research is to examine the impact of social media network follower numbers on corporate share value in an Australian context. So far, the link between social media activities and corporate value seems to be under researched and is mainly restricted to limited studies such as a study from Paniagua and Sapena ${ }^{6}$, who examined the relationship between the two social media platforms Facebook and Twitter and the share returns. They found that the relationship varies 
significantly between the two markets and between the networks and conclude that an investment in Twitter might generate faster returns ${ }^{6}$. As such, to the author's knowledge this study is the first in an Australian context that seeks to link social media network activity to corporate value.

This study makes three key contributions. First, it expands the scope of social media networks to include the professional network, LinkedIn, thus advancing existing research on Facebook and Twitter by adding the largest professional network globally. The exclusion of LinkedIn was noted as a limitation by Paniagua and Sapena ${ }^{6}$. Second, it expands the sample size to increase statistical validity. Prior studies examining a relationship between social media and corporate value are based on relatively small samples, e.g. the study by Luo et al. ${ }^{7}$, is based on a sample of nine corporations, Tirunillai and Tellis ${ }^{8}$ examine 15 corporations and Paniagua and Sapena ${ }^{6}$ study 26 Spanish and nine American companies. Third, the study examines two distinct groups of companies, those operating with a Business-to-Business (B2B) and those with a Businessto-Consumer (B2C) focus. Prior research focuses predominately on $\mathrm{B} 2 \mathrm{C}$ firms 7,8 or do not differentiate between B2B and B2C firms 9,6.

As such, this study is not only a robust extension of prior work as it expands the social media networks to include the professional network LinkedIn, it also focuses on an Australian setting, and improve statistical validity and power by increasing the sample size. Last, this study examines a sample with a clear distinction of business target product markets with two groups, one with a B2B focus and the other with a B2C focus, enabling analysis between the groups.

The remainder of the paper is structured as follows. The next section introduces the social media background and discusses the link between social media and corporate value, developing the two main hypotheses from the literature. This is followed by the methodology and the results section, where the findings from both hypotheses are presented and described. In the final section, the results are discussed and research limitations as well as future research areas are addressed.

\section{Literature review and hypotheses development}

\section{Social media influences}

Firms take note of the rapid expansion of social media to communicate and manage the firm's brand as well as to observe and meet customer preferences ${ }^{8,10,11}$. Observing customer preferences on social media together with the insight gained through access to customer identity and characteristics, can provide valuable input for firms and enable a focused effort, through resources allocation, to meet customer preferences 7 . Firms can tailor products, services, and communication, based on revealed preferences and thus meet customer expectations and needs. The alignment of a brand's communication with the revealed preferences is of benefit to the firm as it is likely to increase the social media network follower numbers and, as a result, improve brand and marketing effectiveness ${ }^{12}$. Research suggests individuals 'like' or follow a firm due to their internalisation and identification with that firm. For example, Leung \& Tanford ${ }^{12}$ found that individuals 'like' a firm's social networking page due to the messages and image of the firm reconciling with the individual's own value system. Other marketing papers focused on several objectives that social media may serve, ranging from brand evaluation, training systems, to different marketing focus between Business-to-Business (B2B) and Business-to-Consumer (B2C) target groups. Rollins et al. ${ }^{13}$ examine the use of blogs for sales training and find that this social media tool is useful learning tool. Swani et al. ${ }^{14}$ study the use of Twitter by B2B and B2C marketers of Fortune 500 companies and expand on the differences between those two groups. The authors find that the usage of social media by $\mathrm{B} 2 \mathrm{C}$ is more emotional than functional. Hollenbeck and Kaikati ${ }^{15}$ study the use of Facebook to represent consumers' actual and ideal identities, which in an extended sense could contribute to the influence of the signal individuals send (through their online identity). The 'liking' or following a commercial page could send a signal about an individual's identification with that brand.

In more corporate focused studies, several authors investigated the effect of social media and 'likes' on customer opinion, purchase intention and sale of products through what is phrased as online "word of mouth" or WOM is investigated. ${ }^{16,17,18,19,20}$ For example, Beukeboom et al. ${ }^{21}$ confirm the link between social media 'likes', brand enhancement and the effect on purchase intention. The researchers evaluate the impact 
of Facebook 'likes' and expand prior research to find a causal relationship between 'liking' a Facebook page and brand evaluation leading to higher purchase intention. Revealed preferences, through brand improvement, increase social and relationship capital as well as improve intellectual capital. Customers' 'liking' generates a closer link between the individual and the firm as well as improves the firm's insights into those individuals ${ }^{22}$.

The amount of 'likes' is also seen as a chance for firms to improve sales performance and hence impact the firm's profitability, which may be reflected in the share price. However, only a few marketing papers6,8, correlate social media network activity to share prices or overall corporate value. The aim of this study is to examine the link between social media activities and corporate value.

\section{The link between social media followers and corporate value}

The financial performance of a firm, as presented in the financial statements and announcements, is a significant component of information used to evaluate a firm's future cash flows and as a result, the share price ${ }^{23}$. However, various other items of information are considered by investors to make predictions on future cash flows and hence are reflected in the share price. Other sources, such as newspaper items, analysts' reports, rating agencies, and the use of those sources of information have been well documented in capital market literature 24,25. More recently, capital market research is being supplemented by studies examining the impact of recent phenomena such as the effects of social media. 6,7,8,9,26,27 Those studies provide for the impact of social media on the corporate value of the firm and reflect that social media matters to investors.

Social media is a communication channel where individuals share experiences including experiences with firms. Those experiences, coined word of mouth (WOM) can affect firm value indirectly through their effects on intangible assets such as the customer equity of the firm. Research shows that customer satisfaction and customer equity influence future expected cash flows, and thereby shareholder value $28,29,30$. Srivastava, Shervani, and Fahey ${ }^{31}$ propose that marketing assets, such as brand equity, create firm value through (1) an acceleration of cash flows, (2) an increase in the level of cash flows, (3) a decrease in the volatility and vulnerability of cash flows, and (4) an enhancement on the residual value of cash flows, which can ultimately be traced to customers. Online WOM through social media can affect consumer decisions to purchase products, thereby translating into future sales, cash flows, and stock performance at an aggregate level.

Customer equity is one of the prominent types of marketing asset measures ${ }^{29}$ and researchers have examined its ability to generate future cash flows. ${ }^{32,33,34}$ Customer equity is recognized as a version of the principle of the present value of a stream of expected future cash flows and thus, is inherently related to a firm value $^{35}$. Customer lifetime value is a further concept which links customer measures to corporate performance. Stahl et al. ${ }^{36}$ propose that customer lifetime value consists of four components: base potential (i.e., cash flow from purchasing products), growth potential (i.e., cash flow from cross-selling and up-trading), networking potential (i.e., cash flow from new relationships through WOM), and learning potential (i.e., cash flow from knowledge creation through interaction). They also argue that customer equity increases shareholder value by enhancing cash flows and reducing volatility of cash flows. Social media network follower numbers are proposed to be a signal of brand value and based on the research outlined above, link to corporate value.

Gupta et al. ${ }^{28}$ found that $1 \%$ improvement in customer retention increases firm value by $5 \%$ whereas $1 \%$ improvement in margin or acquisition costs generates improvements of only $1 \%$ and $0.1 \%$ in firm value, respectively. Kumar and $\mathrm{Shah}^{37}$ found that customer equity, which is determined by the customer lifetime value, can reliably predict the market capitalization of the firm, meaning that changes in customer equity influence the value of the firm. For example, higher incidents of negative WOM imply intense consumer dissatisfaction and thus, firms with higher negative WOM are likely to have a diminishing customer equity that reduces future cash flows ${ }^{38}$.

This study proposes that social media network follower numbers impact the share price because they represent signals about social and relationship capital, intellectual capital and human capital which are intangible assets that lead to financial performance improvements. Based on the assumption of an efficient market, the share price reflects the future cash flows of a firm, assessed on all publicly available information, and discounted through 
a net present value calculation. Arguably, social media network follower numbers provide a signal to the market in relation to future expected cash flows from unrecognised intangible assets. This study contributes to the understanding about the impact of that signal on corporate value.

The consideration that social media is linked to corporate performance is based on the fact that large numbers of individuals spend large amounts of time on social media and provide information while engaging with social media ${ }^{7}$. Further, customers and investors make decisions bearing in mind collective ${ }^{8}$ and believe in social media sentiment ${ }^{26}$. Additionally, investors focus on more visible information, which infers that the more visible and accessible information is within the social media network, the more investors will focus on that information 7 . Tirunillai and Tellis ${ }^{8}$ focused on the impact of social media information on the share price. These authors reviewed how user-generated content is related to stock market performance and concluded that a statistically significant correlation exists. The sample in their study was examined for the volume as well as the inclination of the chatter on product review sites and the correlation to share market returns over a four-year period across six markets and fifteen firms. These researchers produced evidence of a correlation of negative sentiment with negative abnormal return. Furthermore, the volume of chatter was found to have the strongest positive affect on share returns.

This research explores the impact social media network activity has on corporate value in an Australian context to add to the understanding and literature in this field. Hence the following hypothesis is presented for testing:

\section{H1: The social media network follower numbers on Facebook, LinkedIn and Twitter impact the share return of firms.}

The nature of the firm's focus might provide further differentiation. While some firms serve predominantly a Business-to-Business (B2B) market, others operate in a Business-to-Consumer (B2C) market. Brennan and Croft 39 find that $\mathrm{B} 2 \mathrm{~B}$ companies do not display the same usage of social media in comparison to B2C firms. Further, technology companies were predominately found to be active in social media. Prior research on product review sites focused primarily on B2C companies. $7,8,40$ Due to the predominant focus on individuals rather than firms, the relationship between social media network activity and corporate value might be stronger in B2C firms. Social media, specifically social media networking sites are used more extensively in B2C firms than in B2B firms ${ }^{14}$. This study proposes to explore the difference between $\mathrm{B} 2 \mathrm{~B}$ and $\mathrm{B} 2 \mathrm{C}$ firms and the relevant impact on corporate value.

The following hypothesis is therefore advanced for testing:

H2: The relationship between social media network follower numbers and share return is stronger for Business-to-Consumer firms than for Business-toBusiness firms.

\section{Methodology}

Some prior research $7,8,9,41,42$ has empirically tested relationships between social media measures and corporate value, none so far have done this in an Australian setting using social media network follower numbers.

Australian listed companies are chosen as the target population because of the lack of prior research in relation to social media network activity and its relationship to corporate value in this setting. This study draws its sample from the Standard and Poor's (S\&P) ASX200 companies listed on the Australian Securities Exchange (ASX) in June 2016. The S\&P ASX200 represents the 200 largest companies in terms of market capitalisation ${ }^{43}$.

Global industry classification standards (GICS) were used to select the sample for testing. Given the nature of this study, 123 firms classified as belonging to the sectors of Australian Real Estate Investment Trusts (AREITs), Energy, Financials, Financials excluding AREITs, Health Care, Information Technology, Materials, Metals and Mining, Telecommunication Services and Utilities were excluded, leaving 77 companies classified as either Consumer Discretionary, Consumer Staples or Industrials. Three companies were excluded from the sample due to mergers or takeovers, resulting in the final sample consisting of 74 firms.

The inclusion of firms with consumer focus and firms with business focus is based on the expectation that consumer-focused firms utilise social media more than business-to-business focused firms. Thus, the inclusion of the industrial sector enables testing of hypothesis two 
to explore differences between $\mathrm{B} 2 \mathrm{~B}$ and $\mathrm{B} 2 \mathrm{C}$ firms. Previous studies in this field have explored narrow samples such as computer hardware and software industries ${ }^{7}$, IT industries, footwear and toys ${ }^{8}$ or a selection of highly traded shares (Paniagua \& Sapena, 2014). The sample for this study expands on prior research where research was limited to the most traded companies $^{6}$ and social media exposed companies 7,8 . Hence this study expands both sample size and sample scope to advance knowledge in this area.

Data on each sampled firms' daily social media network follower numbers, daily share prices, financial data, and news items were collected for the month of June 2016. For the 74 selected companies in the final sample, the social media network follower data on official social media profiles on Facebook, LinkedIn and Twitter were extracted for analysis. The initial search commenced on each firm's home page. In instances where no links to the social media networks were displayed on the firm's home page, the investor relations and public relations pages of their websites were reviewed. Where no links were published on the firm's website, the firm or brand name was searched on search engines and in each social media network. Each profile identified in this way was accessed and verified to ensure it was the official firmowned profile. Some 36 firms were found to have an official presence on Facebook, 69 on LinkedIn, and 52 on Twitter.

Several firms maintain more than one presence on social media network as presented in Table 1 below.

Table 1. Social media network profiles

Social Media Profiles

\begin{tabular}{lrrcc}
\hline & \multicolumn{2}{l}{ Total no } \\
& $\begin{array}{l}\text { o f } \\
\text { profiles }\end{array}$ & $\begin{array}{l}\text { 1 per } \\
\text { firm }\end{array}$ & $\begin{array}{l}\text { 2 per } \\
\text { firm }\end{array}$ & $\begin{array}{c}3 \text { per } \\
\text { firm }\end{array}$ \\
\hline Facebook & 59 & 29 & 1 & 6 \\
Facebook & 73 & 29 & 0 & 1 \\
Facebook & 112 & 34 & 3 & 15
\end{tabular}

With reference to Table 1, it is clear that while only 36 firms maintain Facebook profiles, seven firms have more than one profile, resulting in data for a total of 59 profiles. Some 69 firms keep a LinkedIn profile, one of which has three or more profiles on this network, giving a total of 73 profiles. Twitter presence is maintained by 52 firms. Some 34 of these hold single profiles, three firms have two profiles, and fifteen firms in the sample have three or more profiles. Thus data were collected for 112 Twitter profiles. The social media analytics website, socialreport.com, was used to collect the daily follower data from these three social media networking sites for the thirty days of June 2016. In line with prior research, share market prices and relevant financial data were extracted from Bloomberg (Paniagua \& Sapena, 2014). Daily opening and closing share prices, news counts, total assets, total liabilities, Earnings before Interest and Taxes (EBIT), the risk free rate, ASX200 index data (AXJO) and daily Fama French factors were collected from Bloomberg and the Dartmouth College website 44 for the 250 trading days leading up to the observation period as well as for the 30 days under observation. All data sets were matched to the relevant social media network follower data using the ASX listing code as the matching key.

The dependent variable for this study is cumulative abnormal return. Abnormal returns are calculated as the difference between raw returns and estimated returns using the Fama French three-factor model ${ }^{45}$. Estimated returns are calculated by estimating the firm coefficients over the estimation period leading up to the observation window.

Various models have been used for time series data including the CAPM and the Fama French three-factor model ${ }^{46}$. The Fama French three-factor model expands on the CAPM by adding a size and a value factor to the market risk factor included in the CAPM. Both models have in common that the parameters are estimated in an out-of-sample period. The assumption is that the parameters for the out-of-sample period do not change in comparison to the in-sample data. Given the sample data are collected over a 30-day period, concerns raised by $\mathrm{Liu}^{46}$ that parameters developed in an out-of-sample period might change for sample periods of multiple years, are not applicable to this study due to the short observation period. Consistent with Tirunillai and Tellis ${ }^{8}$ and Luo et al. ${ }^{7}$, abnormal return is calculated by subtracting the expected return from the actual return.

The use of the Fama French three-factor model for calculating abnormal return is based on prior research. $7,8,47$ Chiah et al.48 argue that the Fama French threefactor model has become the benchmark in asset pricing literature, outperforming the CAPM model. The Fama 
French model has also been tested in the Australian setting and has shown superior predictability power in comparison to the CAPM ${ }^{47}$. It appears the inclusion of factors for size and book-to-market in the Fama French three-factor model improves the CAPM model not only in international studies but also in Australia.

To calculate the abnormal return, the Fama French factors are required. Prior studies 7,8 have extracted the factors from the database provided by Kenneth French on the Dartmouth College website. This study follows prior literature in obtaining the Fama French factors for Asia Pacific (excluding Japan) from the Dartmouth College website . It is acknowledged that the factors published are calculated from a United States investors' point of view and hence are less useful in international applications than US domestic factors for US securities ${ }^{49}$. Calculating the Fama French factors based on Australian data would be preferable but is beyond the scope of this study.

Based on the Fama French three factor model, the firm beta coefficient is estimated for the 250 trading days prior to the observation period. Prior literature uses a pre-estimation window for the factor coefficients of 250 trading days 7,8 and hence this study applies this process. The cumulative abnormal returns are calculated by adding the abnormal return with the prior day cumulative abnormal return.

The independent variables for this study represent the social media follower numbers for Facebook, LinkedIn and Twitter, the social media network presence size for each of those networks as well as the $\mathrm{B} 2 \mathrm{C}$ variable. The variables Facebook, LinkedIn and Twitter are defined as the total follower numbers of the relevant social media profile or profiles for each individual firm normalised by total assets. Finally, B2C is defined as the firm's business orientation based on the firm's global industry classification standard (GICS) grouping as being a member of the Consumer Discretionary, Consumer Staples or Industrial sector, and coded one if the firm has a $\mathrm{B} 2 \mathrm{C}$ orientation and zero otherwise.

A number of control variables are relied on this study. These are firm characteristics and are Earnings, Leverage, News and Size. The Earnings variable controls for the impact of earnings on cumulative abnormal return and is defined as the return on assets. For this study the return on assets is calculated by Earnings before Interest and Taxes (EBIT) divided by the average total assets. The Leverage variable controls for the impact of leverage on cumulative abnormal return and is defined as total debt divided by total assets. The News variable controls for the impact of firm specific news on cumulative abnormal return and is coded one if on day i firm specific news was published, and zero otherwise. Lastly, the Size variable controls for the impact of firm size on cumulative abnormal return and is defined as the log of total assets.

Table 2 provides the definition of each variable used in the study. The cumulative abnormal return variables are the dependent variables while the social media network follower numbers, Facebook, LinkedIn, Twitter, and $\mathrm{B} 2 \mathrm{C}$ variables are the independent variables, the remainder comprise the control variables.

\begin{tabular}{|c|c|c|}
\hline Variable & & Definition \\
\hline$C A R_{-} F F$ & $=$ & $\begin{array}{l}\text { Cumulative Abnormal Return based on Fama } \\
\text { French three-factor model }\end{array}$ \\
\hline Facebook & $=$ & $\begin{array}{l}\text { Total number of Facebook page likes scaled by } \\
\text { total assets }\end{array}$ \\
\hline LinkedIn & $=$ & $\begin{array}{l}\text { Total number of LinkedIn page followers scaled } \\
\text { by total assets }\end{array}$ \\
\hline Twitter & $=$ & $\begin{array}{l}\text { Total number of Twitter page followers scaled by } \\
\text { total assets }\end{array}$ \\
\hline$B 2 C$ & $=$ & $\begin{array}{l}\text { Coded } 1 \text { if a firm is a Business-to-Consumer } \\
\text { firm based on global industry classification } \\
\text { standard, and } 0 \text { otherwise }\end{array}$ \\
\hline Earnings & $=$ & $\begin{array}{l}\text { Return on assets, measured as EBIT/Average } \\
\text { total assets }\end{array}$ \\
\hline Leverage & $=$ & Debt to assets \\
\hline News & $=$ & $\begin{array}{l}\text { Coded } 1 \text { if a firm had firm specific news on day } \\
i \text {, and } 0 \text { otherwise }\end{array}$ \\
\hline Size & $=$ & $\log$ of total assets in $t_{0}$ \\
\hline
\end{tabular}

\section{Results}

Descriptive statistics for social media network follower data by each network are presented in Table 4 .

Table 3. Descriptive Statistics Social Media Network Following Data

\begin{tabular}{ccccc}
\hline Network & Mean & St Dev & Min & Max \\
\hline Facebook & 124,556 & 364,988 & 0 & $2,447,078$ \\
LinkedIn & 13,629 & 24,351 & 0 & 193,207
\end{tabular}


The above data are unscaled. $\mathrm{n}=1,329$

The table above describes the raw social media network follower numbers for the firm profiles extracted for the study. The large follower numbers in terms of mean, standard deviation as well as the range of follower numbers for Facebook reflect the significantly larger user numbers of this social media network. As outlined, the global user numbers for Facebook are significantly larger than those for LinkedIn and Twitter globally and this is equally the case for Australia. LinkedIn, while widely used within the sample firms, does not have the large follower numbers Twitter has. This seems to be sensible as Twitter is a more consumer-focused network than LinkedIn and the large representation of B2C firms in the sample magnifies that effect.

Some 21 firms (28.4\% of sample) belong to the industrial sector and have been categorised as $\mathrm{B} 2 \mathrm{~B}$. The remaining 53 firms $(71.6 \%)$ are in the consumer discretionary and consumer staples sectors and are categorised here as $\mathrm{B} 2 \mathrm{C}$.

The sample is further broken by the number of social media networks to which the firms in each category belong. Table 4 provides a summary.

Table 4. Social Media Network Presence classified by Firm Focus (B2B, B2C).

\begin{tabular}{ccccccc}
\hline $\begin{array}{c}\text { \#of } \\
\text { Networks }\end{array}$ & B2B & $\%$ & B2C & $\%$ & Total & $\%$ \\
\hline 0 & 2 & 9.5 & 1 & 1.9 & 3 & 4.1 \\
1 & 5 & 23.8 & 11 & 20.8 & 16 & 21.6 \\
2 & 7 & 33.3 & 17 & 32.1 & 24 & 32.4 \\
3 & 7 & 33.3 & 24 & 45.3 & 31 & 41.9 \\
\hline Total & 21 & & 53 & & 74 & \\
\hline
\end{tabular}

Taking the sample as a whole, 31 firms (41.9\%) maintain a presence on all three social media networks. Those firms with a presence on two social media networks number 24 (32.4\%), while 16 (21.6\%) firms have one social media network presence, and three $(4.1 \%)$ are not represented on any of the three social media networks.
The firms categorised as B2B maintain social media profiles across all three social media networks with seven $(33.3 \%)$ maintaining a profile on each social media network, a further seven (33.3\%) maintaining a profile on two of the social media networks and five firms $(23.8 \%)$ maintaining one social media profile. Only two firms or $9.5 \%$ of all B2B firms maintain no profile on any of the three social media networks.

Firms in the B2C category maintain higher social media profiles across all three social media networks. Some 24 (45.3\%) firms maintain a profile on each social media network, $17(32.1 \%)$ have profiles on two of the social media networks and 11 (20.8\%) firms maintain one social media profile. Only one firm or $1.9 \%$ of all B2C firms has no representation on any of the social media networks included in this study. It is intuitively sound that firms that focus their business transactions directly with consumers are likely to have a greater presence on social media networks. Thus, the results of Table 5 are not unexpected.

Table 5 reports the descriptive statistics for the total sample. The cumulative abnormal return based on the Fama French three-factor model (CAR_FF) range from -0.120 to 0.111 with a mean of 0.001 and a standard deviation of 0.024 .

The three independent variables Facebook, LinkedIn and Twitter are scaled by total assets. Facebook (Facebook) has a mean of 56.651 (minimum 0, maximum 902.740, standard deviation 171.056), while the mean for LinkedIn (LinkedIn) is 6.370 (minimum 0, maximum 52.070, standard deviation 8.315), and Twitter (Twitter) has a mean of 9.614 (minimum 0 , maximum 333.179, standard deviation 39.067). The final independent variable $\mathrm{B} 2 \mathrm{C}$ is a dichotomous variable, and the mean of 0.716 indicates that $71.6 \%$ of firms are B2C firms.

The four control variables Earnings, Leverage, News and Size as described in Table 6 are presented with their relevant descriptive statistics. Return on Assets (Earnings) has a mean of 0.097 reflecting on a mean return on assets of $9.7 \%$ (minimum -0.115 , maximum 0.408, standard deviation 0.07). Debt to assets (Leverage) has a mean of 0.485 translating in a mean funding of $48.5 \%$ of total assets through debt (minimum 0.032 , maximum 0.91 , standard deviation 0.152 ). News (News) is a dichotomous variable, and the mean of 0.874 indicates that firms have firm-specific news on $87.4 \%$ of observation days. This is to be expected as the 
sample is drawn from the largest listed firms in Australia and it could be assumed that those firms attract regular news coverage. The final control variable is Size (Size) which is the log transformed total asset number for each firm and has a mean of 7.541 (minimum 5.913, maximum 10.616, standard deviation 1.078).

Table 5. Descriptive Statistics Total Sample.

\begin{tabular}{lrcccc}
\hline Variable & $\mathbf{n}$ & Mean & Std Dev & Min & Max \\
\hline CAR_FF & 1329 & 0.001 & 0.024 & 0.024 & 0.111 \\
Facebook & 1329 & 56.651 & 171.056 & 171.056 & 902.740 \\
LinkedIn & 1329 & 6.370 & 8.315 & 8.315 & 52.070 \\
Twitter & 1329 & 9.614 & 39.067 & 39.067 & 333.179 \\
B2C & 1329 & 0.716 & $\mathrm{n} / \mathrm{a}$ & $\mathrm{n} / \mathrm{a}$ & $\mathrm{n} / \mathrm{a}$ \\
Earnings & 1329 & 0.097 & 0.070 & 0.070 & 0.408 \\
Leverage & 1329 & 0.485 & 0.152 & 0.152 & 0.910 \\
News & 1329 & 0.874 & $\mathrm{n} / \mathrm{a}$ & $\mathrm{n} / \mathrm{a}$ & $\mathrm{n} / \mathrm{a}$ \\
Size & 1329 & 7.541 & 1.078 & 1.078 & 10.616 \\
Table 5 (Continued) & & & & \\
\hline
\end{tabular}

$\mathrm{CAR}$ FF $=$ Cumulative Abnormal Return based on Fama French three-factor model, Facebook = Total number of Facebook page 'likes' scaled by total assets, LinkedIn = Total number of LinkedIn page followers scaled by total assets, Twitter $=$ Total number of Twitter page followers scaled by total assets, B2C = Coded 1 if a firm is a Business-to-Consumer firm based on global industry classification standards, and 0 otherwise, Earnings $=$ Return on assets, Leverage $=$ Debt to assets, News $=$ Coded 1 if a firm had firm specific news report, and 0 otherwise, Size $=\log$ of total assets.

This section provides for the results relevant for hypothesis one including relevant tests. Hypothesis one is partially supported for the LinkedIn variable at the $5 \%$ level. Due to the detection of autocorrelation through the Wooldridge test, an autoregressive model was run to test hypothesis one.
Table 6. Results for Autoregressive Model.

\begin{tabular}{|c|c|c|}
\hline VARIABLES & $C A R \_F F$ & Standard error \\
\hline Facebook & -0.001 & 0.001 \\
\hline LinkedIn & $0.0672 * *$ & 0.030 \\
\hline Twitter & 0.003 & 0.007 \\
\hline Earnings & -0.296 & 0.586 \\
\hline News & $-0.002 *$ & 0.001 \\
\hline Size & 0.0928 & 0.291 \\
\hline Constant & -1.095 & 0.845 \\
\hline Observations & 1,255 & \\
\hline Number of firms & 74 & \\
\hline \multicolumn{3}{|c|}{$\begin{array}{l}* * * \mathrm{p}<0.01, * * \mathrm{p}<0.05,{ }^{*} \mathrm{p}<0.1 \\
\mathrm{CAR} \text { FF }=\text { Cumulative Abnormal Return based on Fama French } \\
\text { three-factor model, Facebook }=\text { Total number of Facebook page } \\
\text { 'likes' scaled by total assets, LinkedIn = Total number of LinkedIn } \\
\text { page followers scaled by total assets, Twitter = Total number of } \\
\text { Twitter page followers scaled by total assets, Earnings = Return on } \\
\text { assets, News = Coded } 1 \text { if a firm had firm specific news report and } \\
0 \text { otherwise, Size = Log of total assets. }\end{array}$} \\
\hline
\end{tabular}

Table 6 provides the results for the autoregressive fixed effects model, analysing the impact of the variables of interest on CAR_FF. LinkedIn is the only variable significant at the $5 \%$ level, leading to a significant positive correlation between the membership follower numbers on the social media network LinkedIn and the corporate value of the firm.

In this section the impact of social media network activity and corporate value is examined. A statistically significant difference for LinkedIn-B2C interaction is detected on the cumulative abnormal return, partially supporting hypothesis two for the social media network LinkedIn.

To test hypothesis two, a dichotomous variable is created based on the firm's global industry classification standard (GICS) with Business-to-Consumer firms coded as 1 while the Business-to-Business firms are coded as 0 . This variable, $\mathrm{B} 2 \mathrm{C}$ is included in the regression analysis as well as its interactions with the three social media networks. The results are shown in Table 6 below. 
Table 7. Results for Autoregressive Model - Interactions.

\begin{tabular}{lcc}
\hline VARIABLES & CAR_FF & Standard error \\
\hline Facebook & -0.007 & 0.030 \\
LinkedIn & -0.585 & 0.059 \\
Twitter & $0.546^{*}$ & 0.290 \\
Facebook\#B2C & 0.007 & 0.030 \\
LinkedIn\#B2C & $0.159^{* *}$ & 0.069 \\
Twitter\#B2C & $-0.544^{*}$ & 0.290 \\
Earnings & -0.332 & 0.590 \\
Size & 0.198 & 0.300 \\
News & $-0.002^{*}$ & 0.001 \\
Constant & $-1.898^{* *}$ & 0.879 \\
Observations & 1,255 & \\
Number of firms & 74 & \\
\hline
\end{tabular}

*** $\mathrm{p}<0.01, * * \mathrm{p}<0.05, * \mathrm{p}<0.1$

CAR_FF $=$ Cumulative Abnormal Return based on Fama French three-factor model, Facebook $=$ Total number of Facebook page 'likes' scaled by total assets, LinkedIn $=$ Total number of LinkedIn page followers scaled by total assets, Twitter $=$ Total number of Twitter page followers scaled by total assets, Facebook\#B2C = Facebook-B2C interaction, LinkedIn\#B2C = LinkedIn-B2C interaction, Twitter\#B2C $=$ Twitter-B2C interaction Earnings $=$ Return on assets, Size $=$ Log of total assets, News $=$ Coded 1 if a firm had firm specific news report and 0 otherwise.

Table 7 provides the results for the autoregressive fixed effects model, analysing the impact of the variables of interest on CAR_FF. The LinkedIn-B2C (LinkedIn\#B2C) interaction is significant at the 5\% level and both the Twitter variable and the Twitter-B2C (Twitter\#B2C) interaction are marginally significant at the $10 \%$ level. It is noted that the $\mathrm{B} 2 \mathrm{C}$ variable was omitted due to collinearity with the fixed effects dummy variable.

The null hypothesis claims that there is no significant difference effect of the independent variables or the interactions of the independent variables on a firm's abnormal return. From the results above, we reject the null hypothesis for LinkedIn-B2C (LinkedIn\#B2C) at the 5\% level and for both the Twitter and Twitter-B2C (Twitter\#B2C) interaction at a marginal 10\% level. The null hypothesis is not rejected for the remaining variables. Thus, we conclude that there is a statistically significant impact of a firm's LinkedIn-B2C interaction and cumulative abnormal return and a neglectable, but marginal statistically significant effect for the Twitter and Twitter-B2C interaction on cumulative abnormal return.

From the analysis above and relevant to the objectives of this section it is observed that the outcome of the abnormal return variable does depend on whether the firm has a consumer or business orientation at the $5 \%$ level.

\section{Discussion}

Having analysed and addressed the relationship between social media network follower numbers and corporate value in Australia, several important findings have been identified worthy of further discussions.

First, given the lack of research in an Australian context, the first hypothesis proposed that Australian social media network follower numbers on Facebook, LinkedIn and Twitter have an impact on the share return. In particular, the hypothesis was tested by initially establishing whether the social media network follower size overall, and on each individual social media network, had an effect on the cumulative abnormal return. The results are partially supportive of the hypothesis, showing that the social media presence on LinkedIn has a positive statistically significant effect on cumulative abnormal return. The social media presence on Facebook and Twitter can be regarded as having no effect, albeit those results might be masked in the data.

The findings compare with prior studies in adding to the understanding of the impact of social media network follower numbers on corporate value in Australia. Prior studies have found that the presence on social media impacts performance ${ }^{9}$, the volume and sentiment of chatter on social media impacts performance ${ }^{7,8}$, and social media network follower numbers impact performance in Spain and the United States ${ }^{6}$.

Second, based on prior research showing different levels of engagement with social media network following based on the industry a business operates in, the second hypothesis proposed that the relationship between social media network follower numbers and share return is stronger for Business-to-Consumer (B2C) firms than for Business-to-Business (B2B) firms. The results show a 
statistically significant impact between LinkedIn-B2C interaction and a marginal significant effect for TwitterB2C interaction on share returns. Thus hypothesis two is partially supported. This is interesting insofar, as differences can be observed in social media activities between B2B and B2C firms ${ }^{50,51}$. For example, Stelzner ${ }^{52}$ found that $\mathrm{B} 2 \mathrm{C}$ firms are more focused on Facebook, while B2B firms are more focused on LinkedIn and Twitter. As such, the results extend prior findings and thereby advance the body of knowledge in the field of social media activities of firms. However, the lack of statistically significant results across all three social media networks may indicate that too much noise is present in the model analysed. The research limitations and future research opportunities in the following sections provide for considerations on how limitations could be addressed and future research conducted to explore this relationship further and with more specific outcomes.

\section{Conclusion, limitations and implications for further research}

\section{Key findings and contribution to literature}

The findings of this study provide an insight into the relationship between social media network follower numbers and corporate value. As such, the results advance the literature by contributing to the knowledge and by narrowing the gap in the understanding of how social media network activity correlate to corporate value. The study revealed that social media network follower numbers do have an impact on corporate performance. Social media network follower numbers provide a link between social media and corporate value, but the link is mainly restricted to LinkedIn, marginally Twitter and rather excluding Facebook.

\section{Practical Implications}

For practice, the study provides managers with an additional resource to refer to when discussing and evaluation the firm's investments into social media. As outlined in earlier sections, social media use is growing globally and businesses have an interest in utilising social media. Managers require a deeper understanding of social media opportunities and returns to allocate resources. The scope of studies in the marketing literature predominantly focuses on marketing-specific outcomes such as customer engagement, brand value and purchase intention, to name a few. There is a need for accounting focused studies which study measures that link social media investments with financial performance.

\section{Research limitations and future research direction}

Several limitations apply to this study and are opportunities for further research and refinement. The sample and observation length selected are recognised as limitations and by increasing the sample size, expanding industry sectors and extending the observation period, further insights can be gained. Independent and control variables could also be expanded and refined. For example, the social media investment by a firm could be included as a variable. Additional insight could be derived by researching the effect of social media network follower numbers on specific future financial performance and ratios. Given the brand value signal impounded in the social media network follower numbers it is possible that the impact of this signal is on specific measures such as revenue, return on assets etc.

\section{References.}

1. Statista, Number of Facebook users worldwide 2008-2016 (2016a), Retrieved 04/01/2017, from https:// www.statista.com/statistics/264810/number-of-monthlyactive-facebook-users-worldwide/

2. Statista, Numbers of LinkedIn members 2009-2016 (2016b), Retrieved 04/01/2017, from https:// www.statista.com/statistics/274050/quarterly-numbersof-linkedin-members/

3. Statista, Twitter: number of monthly active users 2010-2016 (2016c), Retrieved 04/01/2017, from https:// www.statista.com/statistics/282087/number-of-monthlyactive-twitter-users/

4. S. Wilde, Social Media in Micro and Small Third Sector Firms, The International Technology Management Review, 5(3), (2015) 135-141.

5. S.J. Wilde, D. M. Herold and N. Herold, European nonprofit SME's use of social media: Driving innovation and entrepreneurship in the third sector. In 5th International Conference on Contemporary Marketing Issues ICCMI June 21-23, 2017 (Thessaloniki, Greece, 2017), p. 437.

6. J. Paniagua and J. Sapena, Business performance and social media: Love or hate? Business Horizons, 57(6) (2014) 719-728. 
7. X. Luo, J. Zhang and W. Duan, Social Media and Firm Equity Value. Information Systems Research, 24(1) (2013) 146-163.

8. S. Tirunillai and G. J. Tellis, Does Chatter Really Matter? Dynamics of User-Generated Content and Stock Performance. Marketing Science, 31(2) (2012) 198-215.

9. H. Du and W. Jiang, Do Social Media Matter? Initial Empirical Evidence. Journal of Information Systems, 29(2) (2015) 51-70.

10. S. J. Wilde, P. Gillett, D. M. Herold and O. Hogan, The market orientation of Australian nonprofit SMEs. International Journal of Business and Management Studies, 4(2) (2015) 403.

11.P. A. P. Correia, I. G. Medina, Z. F. G. Romo and R. S. Contreras-Espinosa, The importance of Facebook as an online social networking tool for companies. International Journal of Accounting \& Information Management, 22(4), (2014) 295-320.

12.X. Y. Leung and S. Tanford, What Drives Facebook Fans to "Like" Hotel Pages: A Comparison of Three Competing Models. Journal of Hospitality Marketing \& Management, 1-32 (2015).

13.M. Rollins, D. Nickell and J. Wei, Understanding salespeople's learning experiences through blogging: A social learning approach. Industrial Marketing Management, 43(6) (2014) 1063-1069.

14.K. Swani, B. P. Brown and G. R. Milne, Should tweets differ for B2B and B2C? An analysis of Fortune 500 companies' Twitter communications. Industrial Marketing Management, 43(5) (2014) 873-881.

15.C. R. Hollenbeck and A. M. Kaikati, Consumers' use of brands to reflect their actual and ideal selves on Facebook. International Journal of Research in Marketing, 29(4) (2012) 395-405.

16.J. Berger, A. T. and S. J. Rasmussen, Positive Effects of Negative Publicity: When Negative Reviews Increase Sales. Marketing Science, 29(5) (2010) 815-827.

17.J.A. Chevalier and D. Mayzlin, The Effect of Word of Mouth on Sales: Online Book Reviews. Journal of Marketing Research, 43(3) (2006) 345-354.

18.C. Dellarocas, X. Zhang, and N. F. Awad, Exploring the value of online product reviews in forecasting sales: The case of motion pictures. Journal of Interactive Marketing, 21(4) (2007) 23-45.

19. G. Prendergast, D. Ko and V. Y. Siu Yin. Online word of mouth and consumer purchase intentions. International Journal of Advertising, 29(5) (2010) 687-708.

20.D. M. Herold, F. Manwa, S. Sen and S. Wilde, It's the yeast we can do: Untapping Sustainability Trends in Australian Craft Breweries. Journal of Asia Entrepreneurship and Sustainability, 12(2) (2016) 82.

21.C. J. Beukeboom, P. Kerkhof and M. de Vries, Does a Virtual Like Cause Actual Liking? How Following a Brand's Facebook Updates Enhances Brand Evaluations and Purchase Intention. Journal of Interactive Marketing, 32 (2015) 26-36.
22.I. Vilnai-Yavetz and S. Tifferet, A Picture Is Worth a Thousand Words: Segmenting Consumers by Facebook Profile Images. Journal of Interactive Marketing, 32 (2015) 53-69.

23.S. P. Kothari, Capital markets research in accounting. Journal of Accounting and Economics, 31(1-3) (2001) 105-231.

24.P. M. Healy and K. G. Palepu, Information asymmetry, corporate disclosure, and the capital markets: A review of the empirical disclosure literature. Journal of Accounting and Economics, 31(1-3) (2001) 405-440.

25.E. Amir and B. Lev, Value-relevance of nonfinancial information: The wireless communications industry. Journal of Accounting and Economics, 22(1) (1996) 3-30.

26.E. Bartov, L. Faurel and P. Mohanram, Can Twitter Help Predict Firm-Level Earnings and Stock Returns? (2015).

27. N. Hyoryung and P. K. Kannan, The Informational Value of Social Tagging Networks. Journal of Marketing, 78(4) (2014) 21-40.

28.S. Gupta, D. R. Lehmann and J. A. Stuart, Valuing customers. Journal of Marketing Research, 41(1) (2004) 7-18.

29. R. T. Rust, K. N. Lemon and V. A. Zeithaml, Return on Marketing: Using Customer Equity to Focus Marketing Strategy. Journal of Marketing, 68(1) (2004) 109-127.

30.K. H. Lee and D. M. Herold, Cultural relevance in corporate sustainability management: a comparison between Korea and Japan. Asian Journal of Sustainability and Social Responsibility, (2016) 1.

31.R. K. Srivastava, T. A. Shervani and L. Fahey, Marketbased assets and shareholder value: A framework for analysis. The Journal of Marketing (1998), 2-18.

32.G. N. Bick, Increasing shareholder value through building customer and brand equity. Journal of Marketing Management, 25(1-2) (2009) 117-141.

33.X. Luo and C. Homburg, Neglected outcomes of customer satisfaction. Journal of Marketing, 71(2) (2007) 133-149.

34.K. R. Tuli and S. G. Bharadwaj, Customer satisfaction and stock returns risk. Journal of Marketing, 73(6) (2009) 184-197.

35. S. Srinivasan and D. M. Hanssens, Marketing and Firm Value: Metrics, Methods, Findings, and Future Directions. Journal of Marketing Research, 46(3) (2009) 293-312.

36.H. K. Stahl, K. Matzler and H. H. Hinterhuber, Linking customer lifetime value with shareholder value. Industrial Marketing Management, 32(4) (2003) 267-279.

37. V. Kumar and D. Shah, Expanding the role of marketing: from customer equity to market capitalization. Journal of Marketing, 73(6) (2009) 119-136.

38.R. A. Riley, T. A. Pearson and G. Trompeter, The value relevance of non-financial performance variables and accounting information: the case of the airline industry. 
Journal of Accounting and Public Policy, 22(3) (2003) 231-254.

39. R. Brennan and R. Croft, The use of social media in B2B marketing and branding: An exploratory study. Journal of Customer Behaviour, 11(2) (2012) 101-115.

40.D. M. Herold, Corporate social responsibility (CSR) als kaufentscheidungskriterium im B2B-bereich, (2009).

41.P. M. Clarkson, D. Joyce and I. Tutticci, Market reaction to takeover rumour in Internet Discussion Sites. Accounting \& Finance, 46(1) (2006) 31-52.

42. A. J. O'Connor, The Power of Popularity: An Empirical Study of the Relationship Between Social Media Fan Counts and Brand Company Stock Prices. Social Science Computer Review, 31(2) (2013) 229-235.

43.T. M. Carlin and N. Finch, Goodwill impairment testing under IFRS: a false impossible shore? Pacific Accounting Review, 23(3) (2011) 368-392.

44.K. R. French, Data Library (2017), Retrieved 26/01/2017, from http://mba.tuck.dartmouth.edu/pages/ faculty/ken.french/data_library.html

45.E. F. Fama and K. R. French, Common risk factors in the returns on stocks and bonds. Journal of Financial Economics, 33(1) (1993) 3-56.

46. Y. Liu, An Examination of the Long-run Market Reaction to the Announcement of Dividend Omissions and Reductions (Drexel University, Hagerty Library, 2003).

47.T. Brailsford, C. Gaunt and M. A. O'Brien, Size and book-to-market factors in Australia. Australian Journal of Management, 37(2) (2012) 261-281.

48. M. Chiah, D. Chai and A Zhong, A Better Model? An Empirical Investigation of the Fama-French Five-Factor Model in Australia (2015).

49.J. M. Griffin, Are the Fama and French factors global or country specific? Review of Financial Studies, 15(3) (2002) 783-803.

50.N. Michaelidou, N. T. Siamagka, N.T. and G. Christodoulides, Usage, barriers and measurement of social media marketing: An exploratory investigation of small and medium B2B brands. Industrial marketing management, 40(7) (2011) 1153-1159.

51.K.H. Lee, D. M. Herold and A. L. Yu, Small and medium enterprises and corporate social responsibility practice: A Swedish perspective. Corporate Social Responsibility and Environmental Management, 23(2) (2016) 88-99.

52. M. Stelzner, The 2011 social media marketing industry report. Social Media Examiner, (2011) 7. 